\title{
Association of Oxidative Stress on Pregnancy
}

\author{
Kinga Toboła-Wróbel $\mathbb{D},{ }^{1}$ Marek Pietryga $\mathbb{D},{ }^{1,2}$ Piotr Dydowicz, ${ }^{2}$ Marta Napierała $\mathbb{D},{ }^{3}$ \\ Jacek Brązert, ${ }^{1}$ and Ewa Florek $\mathbb{1}^{3}$ \\ ${ }^{1}$ Department of Obstetrics and Female Health, Chair of Gynaecology, Obstetrics and Gynaecological Oncology, Poznan University of \\ Medical Sciences, 60-535 Poznan, Poland \\ ${ }^{2}$ Ultrasound and Prenatal Diagnostic Laboratory, Gynaecology and Obstetrics Hospital, Poznan University of Medical Sciences, \\ 60-535 Poznan, Poland \\ ${ }^{3}$ Laboratory of Environmental Research, Department of Toxicology, Poznan University of Medical Sciences, 60-631 Poznan, Poland
}

Correspondence should be addressed to Kinga Toboła-Wróbel; kingatob90@gmail.com

Received 15 April 2020; Revised 19 August 2020; Accepted 1 September 2020; Published 15 September 2020

Academic Editor: Hassan Obied

Copyright (C) 2020 Kinga Toboła-Wróbel et al. This is an open access article distributed under the Creative Commons Attribution License, which permits unrestricted use, distribution, and reproduction in any medium, provided the original work is properly cited.

\begin{abstract}
The pathophysiological mechanism underlying pregnancy complications such as congenital malformations, miscarriage, preeclampsia, or fetal growth restriction is not entirely known. However, the negative impact of the mother's body oxidative imbalance on the fetus and the course of gestation is increasingly discussed. This article is an integrative review of some original studies and review papers on the effects of oxidative stress on the adverse pregnancy outcomes mainly birth defects in fetuses. A systematic search for English language articles published from 2010 until 2020 was made, using MEDLINE data. Additionally, we analyzed the Cochrane and Scopus databases, discussions with experts, and a review of bibliography of articles from scientifically relevant and valuable sources. The main purposes are to assess the contribution of the existing literature of associations of oxidative stress on the etiology of the abovementioned conditions and to identify relevant information and outline existing knowledge. Furthermore, the authors aim to find any gaps in the research, thereby providing grounds for our own research. The key search terms were "oxidative stress in pregnancy," "oxidative stress and congenital malformations," and "oxidative stress and adverse pregnancy outcomes." Studies have confirmed that oxidative stress has a significant impact on pregnancy and is involved in the pathomechanism of adverse pregnancy outcomes.
\end{abstract}

\section{Introduction}

Over the past few years, more and more attention has been devoted to issues of environmental impact, lifestyle, and comorbidities on the body's oxidative balance and its possible impact on abnormalities related to fetal development and pregnancy outcome. The term oxidative stress refers to the imbalance between the production of reactive oxygen species (ROS) and the ability of antioxidant mechanisms to neutralize them. It may be the result of an increase in ROS generation and/or a weakening of antioxidant defense [1, 2]. Analyzing the available literature of the last decade, it has been found that the topic of oxidative stress in pregnancy is becoming more common and knowledge on this subject is expanding.
The causative factor of the analysis is the previously unexplained etiology of most frequent pregnancy complications, such as miscarriages, FGR, or preeclampsia, in particular congenital defects. The main purposes are to assess the contribution of existing literature of the association of oxidative stress on the etiology of the abovementioned conditions and to identify relevant information and outline existing knowledge. Furthermore, the authors aim to find any gaps in the research, thereby providing grounds for our own research.

The article is an integrative overview of the original studies and review papers concerning the role of oxidative stress in the pathogenesis of pregnancy complications with particular emphasis on congenital defects and chromosomal aberrations. A review of articles published from 2010 to 2020 in 
English has been carried out by searching the MEDLINE database using the terms "oxidative stress in pregnancy," "oxidative stress and congenital malformations," and "oxidative stress and adverse pregnancy outcomes." Additional search has been carried out using the analyses of the Cochrane and Scopus databases, discussions with experts, and a review of bibliography of articles from scientifically relevant and valuable sources.

The research strategy is attached as Table 1.

To sum up, the main question to which the authors seek the answers to in this article is: "Does oxidative stress have a significant impact on the course of pregnancy and the occurrence of birth defects?"

\section{The Body's Prooxidative and Antioxidant System}

Reactive oxygen species (ROS) are products of the body's incomplete reduction of oxygen molecules. They oxidize fats, proteins, and DNA and thus can contribute to tissue damage. Toxic oxidation reaction products exert a cytostatic effect on the cell, damage cell membranes, and activate mechanisms of apoptosis. The ROS includes superoxide anion radical $(\mathrm{O} 2 \bullet)$, hydroxyl radical $(\mathrm{OH} \bullet)$, hydroperoxide radical $(\mathrm{HO} 2 \bullet)$, peroxide radical $(\mathrm{ROO} \bullet)$, and alkoxy radical $(\mathrm{RO} \bullet)$ and others: hydrogen peroxide ( $\mathrm{H} 2 \mathrm{O} 2)$, hypochlorous acid $(\mathrm{HOCl})$, and subbromic acid (HOBr) [3-5].

The body has also developed an antioxidant system consisting of preventing, combating, eliminating, and repairing the effects of ROS reactions with biological molecules to defend against them. Due to the mechanism of action, antioxidants can be divided into enzymatic: superoxide dismutase (SOD), catalase (CAT), glutathione peroxidase (GSH$\mathrm{Px})$, ceruloplasmin, heme proteins, thioredoxin (TRX), and paraoxonase (PON1) and nonenzymatic: glutathione (GSH), vitamin E, vitamin C, albumin, bilirubin, uric acid, creatinine, cysteine, carotenoids, flavonoids, coenzyme Q (reduced), metal ion binding proteins (ferritin, metallothioneins), and blood plasma proteins (transferrin, ceruloplasmin, albumin) [6-10].

The list of disease entities in which the causative and negative effects of oxidative stress has been proven to increase as research into the mechanisms of its action develops [11-16].

The studies carried out so far concern the occurrence of oxidative stress in the body by increased concentrations of lipid peroxidation products and reduced activity of antioxidant enzymes or other antioxidants. [17-20] These reduced values of oxidative enzymes can disturb the body's prooxidative-antioxidative homeostasis by participating in the pathogenesis of diseases, and increased values of oxidative stress can be a symptom of an adaptive reaction and an attempt to alleviate the effects of these pathological changes $[21,22]$.

Pregnancy is a time when the body's oxidative imbalance negatively affects its development and causes various types of complications depending on the stage of its development. This mechanism is described in Figure 1.

The relationship between abnormal metabolism, disturbances in ROS production, the body's oxidative balance, and diseases can be the cause, stage, or effect of a disease process. Currently, it is not possible to clearly define the direction of changes, but it is increasingly emphasized as the role of causative factor [23].

\section{Oxidative Stress in Pregnancy with Normal Pregnancy Outcome}

During physiological pregnancy, the development of fetal tissues and organs requires the supply of an adequate amount of nutrients and oxygen, and its reactive forms produced in the body of the mother and the fetus affect the replication, differentiation, and maturation of the developing cells. Their balanced activity and maintaining the balance of oxidative processes are necessary factors for the proper development and functioning of the body [24].

During pregnancy, numerous anatomical, physiological, and metabolic changes occur in the mother's body. According to the researchers, it is assumed that they support the production of ROS, especially in the second half of pregnancy. This is mainly due to an increasing basic metabolism and "consumption" of oxygen and the use of fatty acids as the primary source of energy for most maternal retroplacental tissues. The last trimester of pregnancy is a special period of increasing insulin resistance, fat catabolism, and the release of free fatty acids. These processes lead to increased production of hydrogen peroxide [25].

The placenta, filled with mitochondria, is the main source of prooxygenates, the so-called ROS "factory." The superoxide anion radical $(\mathrm{O}-\bullet 2)$ produced in large quantity is a source of the formation of further active forms of oxygen, i.e., hydrogen peroxide and hydroxyl radical. Their production increases with the development of pregnancy, which is mainly associated with an increase in placental mass. Nitric oxide is also synthesized by macrophages mainly in the placenta.

In a correctly developing pregnancy, the phenomenon of the mother's immune tolerance to the fetus' antigens, which allows the fetus to develop in the uterus despite the pregnant woman's ability to reject the foreign antigen, is an extremely important aspect. The main assumptions of this phenomenon are partial inhibition of the mother's immune system during pregnancy, insufficiently strong presentation of fetal antigens, the placenta as an important element separating the woman from the fetus, and changing the direction of the organism's specific response to the Th2 response instead of Th1 (cytokines produced mainly by nonspecific system cells-NK type (natural killer)). Immunological tolerance is therefore formed by the cells of the implanted trophoblast, the mother's immune system, and the microenvironment of the implanted embryo-a decidual cell. It enables the correct implantation and development of the embryo and functioning of the placenta. Due to the reduction of the immune system works in a properly functioning pregnant organism, the production of ROS is lowered.

Erythropoiesis increases, erythrocyte life expectancy decreases, and increased iron delivery to the fetus increases its availability by catalyzing the increase in the generation of large amounts of reactive hydroxyl $(\bullet \mathrm{OH})$ radicals in the Fenton reaction [26]. 
TABLE 1: Search strategy.

\begin{tabular}{ll}
\hline Search strategy & \\
\hline Purposes & (i) Assess the contribution of existing literature of association of oxidative stress on the etiology of pregnancy \\
complications (miscarriages, congenital malformations/chromosomal abnormalities, FGR, preeclampsia) & (ii) Identify relevant information and outline existing knowledge \\
& (iii) Identify any gap in the research thereby providing a rationale for our own studies \\
\hline Research & (i) Does oxidative stress have a significant impact on the occurrence of disorders during pregnancy, and in particular birth \\
question & defects in the fetus? \\
\hline & (i) "Oxidative stress in pregnancy" \\
Keywords & (ii) "Oxidative stress and congenital malformations" \\
& (iii) "Oxidative stress and adverse pregnancy outcomes"
\end{tabular}

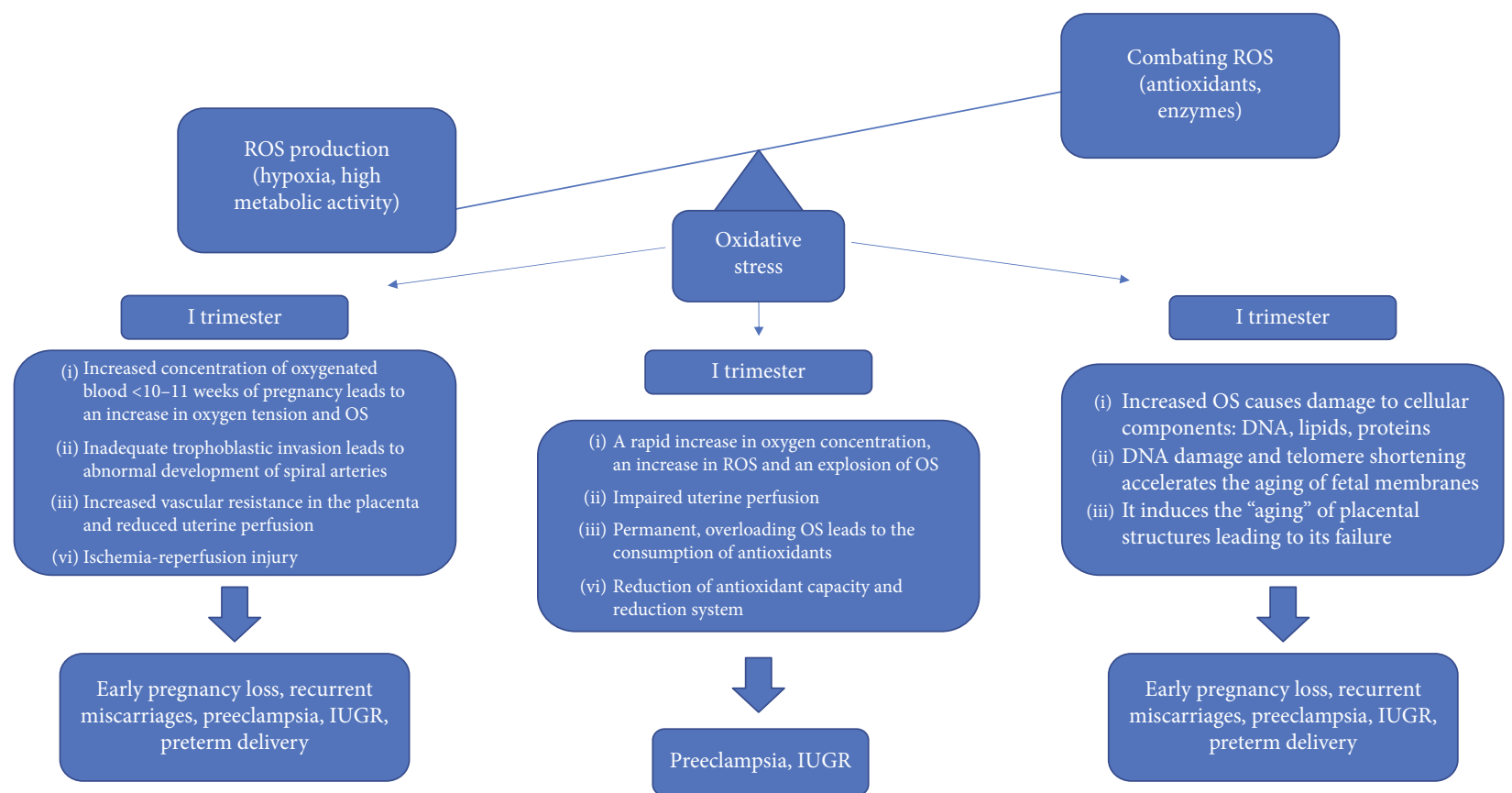

FIGURE 1: Impact of oxidative stress on function and abnormal pregnancy development [23].

Numerous studies prove that oxidative stress, i.e., excessive and unbalanced ROS production, has adverse effects on pregnancy, pregnant health, and fetal development. It is the cause of incorrect implantation of embryos, miscarriages, premature births, low birth weight, and malformations. It also weakens pregnant immunity and respiratory adaptation of newborns immediately after birth. The main reason for these disorders is the insufficient supply of nutrients and oxygen to the fetus resulting mainly from hypoplasia and abnormal placental function [23-25].

Comparative studies of pregnant and nonpregnant patients [27] showed that total plasma antioxidant status (TAS) in the first trimester of pregnancy is significantly lower. In the second and third trimesters of pregnancy, total plasma antioxidant capacity (TAC) increases, and in the last week of pregnancy reaching values similar to those observed in nonpregnant women. After delivery, this rate increases to the eighth week after delivery, and these changes are proportional to changes in plasma uric acid.
Studies by other scientists indicate that the reason for lower TAS values in pregnancy is the reduction in serum albumin, bilirubin, and vitamin E levels [28]. It was also found that during a properly developing pregnancy, plasma superoxide dismutase activity decreases [29].

Physiologically, during pregnancy, it increases the concentration of triglycerides, total cholesterol, and low-density lipoprotein (LDL) cholesterol levels in plasma as well as markers of oxidative stress, which is associated with an increase in lipid peroxides after 25 weeks of pregnancy. Therefore, the natural indicator of oxidative stress and the degree of lipid peroxidation is increasing concentration of malondialdehyde in the plasma of pregnant women.

There have also been reports of the effect of a diet with vitamins, antioxidants, and minerals on the value of total antioxidant status in pregnant patients [28-30].

The potential influence of antioxidant and vitamin supplementation on the course of pregnancy is shown in Table 2. 
TABLE 2: Effect of vitamins, micronutrients, and antioxidants on pregnancy outcome.

\begin{tabular}{|c|c|c|c|}
\hline References & Markers analyzed & Disease units analysed & Commentary \\
\hline $\begin{array}{l}\text { Dennery } \\
\text { [28] (USA) }\end{array}$ & $\begin{array}{c}\text { Lazaroid-new class of lipophilic steroids } \\
\text { Polyunsaturated fatty acids (PUFAs) } \\
\text { Vitamin C and E-antioxidant }\end{array}$ & $\begin{array}{c}\text { Vascular dysfunction of } \\
\text { the mother } \\
\text { Hypertension } \\
\text { IUGR }\end{array}$ & $\begin{array}{c}\text { Administration of lazaroid }=\downarrow \text { risk in offspring. } \\
\text { Melatonin solution administration }=\downarrow \text { risk of } \\
\text { oxidative DNA damage }(\downarrow \text { IUGR cases }) \\
\text { PUFAs administration }=\uparrow \text { ROS in } \\
\text { oocytes }=\text { impaired embryonic development } \\
\text { Combined vitamin C and E } \\
\text { supplementation }=\text { not useful in preventing } \\
\text { preeclampsia }\end{array}$ \\
\hline
\end{tabular}

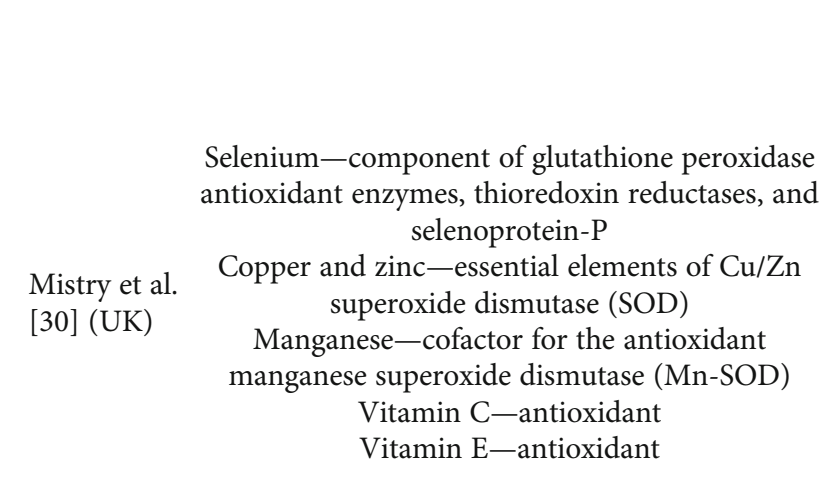

Reccurent pregnancy loss (RPL)

Postpartum thyroid

dysfunction (PPTD)

Preeclampsia (PE)

pregnancy-induced

hypertension (PIH)

Prolonged labour

Fetal growth restriction (FGR)

Embryonic or fetal death

Perinatal death

Preterm prelabour rupture of membranes (PPROM)

\author{
In mother's serum: $\downarrow$ selenium \\ concentrations $=\uparrow$ risk of $\mathrm{RPL}$ \\ Selenium supplementation (women positive for \\ thyroid peroxidase antibodies $)=\downarrow$ risk for \\ PPTD, PE, and PIH \\ Copper itself $=$ acting as a prooxidant, \\ associated in $\mathrm{Cu} / \mathrm{Zn} \mathrm{SOD}=$ acting as an \\ antioxidant \\ Zinc supplementation $=\downarrow$ risk of PIH and low \\ birth weights \\ $\downarrow$ manganese concentrations $=\uparrow$ risk of FGR \\ Vitamin C and E supplementations = no \\ impact on PE and PIH, $\uparrow$ risk of fetal loss, \\ perinatal death and PPROM
}

\begin{tabular}{l}
$\begin{array}{l}\text { Pasiński } \\
\text { et al. [53] } \\
\text { (Poland) }\end{array}$ \\
\hline $\begin{array}{l}\text { Vitamin C-antioxidant } \\
\text { Oxidative Stress in Pregnancy } \\
\text { Completed with Birth Defects (Table 3) }\end{array}$
\end{tabular}

The problem of birth defects in the fetus concerns about $4-6 \%$ of live-born newborns and the majority of miscarriages in the first trimester of pregnancy, the exact number of which cannot be determined. They are also the most common cause of infant mortality and disability in the 21 st century. The most commonly known causes of congenital defects are genetic factors. However, approximately $50 \%$ of congenital anomalies cannot be linked to a specific cause.

Oxidative stress, which is primarily the result of excessive production of oxygen peroxidation products, mainly in mitochondria, attacks newly growing cells. It damages their structures probably already at an early stage of embryogenesis. Determinants of the production of an increased number of ROS and disorders caused by them can be environmental pollution, chronic stress, low levels of physical activity, teratogenic effect of drugs and chemicals, or improper nutrition. It causes abnormalities in the structure of DNA that can lead to early miscarriages, preeclampsia, fetal growth restriction, fetal abnormalities, and birth defects [31-33].

Researchers found elevated levels of oxidative stress markers in the blood serum of pregnant mothers during the first prenatal examination at 11-14 gestational week, who had a high ( $<1: 300$ according to Fetal Medicine Foundation) risk of fetal malformations. Then, after further research and detailed analysis, they confirmed the significant difference
Preeclampsia (PE)

pregnancy-induced hypertension $(\mathrm{PIH})$
Vitamin C and E supplementations $=\downarrow$ lipid peroxides and ROS between the levels of oxidative stress in patients with healthy and diseased fetuses-complicated by chromosomal aberrations and other malformations [34].

Due to the damage of the DNA structure by an unbalanced antioxidative and oxidative level in the body, more attention is paid to the role of ROS in the etiopathogenesis of genetic defects. Oxidative stress damaging the structure of a deoxyribonucleic acid molecule leads to chromosomal aberrations. Pagano and Castello [35] showed characteristic changes in vivo of mitochondrial function, leading to increased ROS concentration in the cell as changes characteristic of trisomy 21. Analyses of several markers of oxidative stress, in pregnant blood, amniotic fluid, and fetal tissues clearly showed its association with Down syndrome. Observed changes had a significant share in the damage of various tissue enzymes. It can be presumed that they played a role in the pathogenesis of this abnormality [36].

The metabolomic analysis of blood serum from patients with Down syndrome in the fetus, in the first trimester of pregnancy, showed differences in the levels of 2hydroxybutyrate in comparison with patients with healthy fetuses. The level of substance, which is physiologically involved in the defense against oxidative stress, was lower in the study group, proving the oxidative imbalance in the pregnant body with fetal trisomy 21 [37].

There was also a conducted research about the rate of fibroblast proliferation and its major regulators, such as Rcan1 or telomere length, for assessing the oxidative balance of these cells in fetuses with Down syndrome. RNA 
TABLE 3: Current studies concerning the influence of oxidative stress on congenital malformations.

\begin{tabular}{|c|c|c|c|}
\hline References & Markers analyzed & Abnormalities investigated & Commentary \\
\hline $\begin{array}{l}\text { Hernández- } \\
\text { García et al. [29] } \\
\text { (Mexico) }\end{array}$ & $\begin{array}{c}\text { Dichlorofluorescin (DCFH) } \\
3^{\prime} \text {-(p-Aminophenyl) fluorescein } \\
\text { (APF) } \\
3^{\prime} \text {-(p-Hydroxyphenyl) } \\
\text { Fluorescein (HPF) } \\
\text { Hydroethidine (HE) } \\
\text { Dihydrorhodamine (DHR) } \\
\text { Mono- and diboronated sensors } \\
\text { Boron dipyrromethene difluoride } \\
\text { (BODIPY-) based dyes } \\
\text { Hydrocyanines }\end{array}$ & Cell development-early embryogenesis & $\begin{array}{l}\text { Review: uncertain and unspecific evidence } \\
\text { on the role of ROS in development. } \\
\text { Assessment of recent methods to detect } \\
\text { ROS in vivo-markers of cellular ROS } \\
\text { production in embryos }\end{array}$ \\
\hline $\begin{array}{l}\text { Dennery [28] } \\
\text { (USA) }\end{array}$ & Reactive oxygen species (ROS) & Human development & $\begin{array}{l}\text { Review: impact of redox state on fetal } \\
\text { development and placenta } \\
\text { High ROS levels cause impairment fetal } \\
\text { development and placental function } \\
\text { Possible therapeutic interventions with } \\
\text { antioxidant: Vit C and E- uncertain }\end{array}$ \\
\hline $\begin{array}{l}\text { Bahado-Singh } \\
\text { et al. [37] (USA) }\end{array}$ & $\begin{array}{c}\text { Male gender } \\
\text { Oxidative stress } \\
\text { 8-Hyroxy-2-deoxyguauosine, } \\
\text { glutathione, vitamin A }\end{array}$ & $\begin{array}{l}\text { Cyanotic congenital heart disease } \\
\text { (CCHD), anencephaly, spina bifida, } \\
\text { congenital diaphragmatic hernia (CDH), } \\
\text { omphalocele, gastroschisis, limb defects, } \\
\text { cleft lip with or without cleft palate } \\
\text { (CL/P), and isolated cleft palate }\end{array}$ & $\begin{array}{c}\text { Increased OS in males } \\
\text { Development of CCHD, omphalocele, } \\
\text { neural tube, and facial cleft is linked to } \\
\text { increased OS } \\
(\uparrow 8 \text {-hyroxy-2-deoxyguauosine, } \\
\text { glutathione) ( } \downarrow \text { vitamin } A)\end{array}$ \\
\hline
\end{tabular}

Protein carbonylation

Protein-bound HNE

Perluigi et al. $\quad$ Reduced glutathione (GSH)

[39] (Italy) Heat shock proteins (HSPs)

Thioredoxin (Trx)

\begin{tabular}{lccc}
\hline $\begin{array}{l}\text { Piccoli et al. [44] } \\
\text { (Italy) }\end{array}$ & $\begin{array}{c}\text { Mitochondrial respiratory } \\
\text { activity } \\
\text { Reactive oxygen species (ROS) }\end{array}$ & $\begin{array}{c}\text { Down syndrome } \\
\text { Congenital heart defects }\end{array}$ & $\begin{array}{c}\text { Mitochondrial disfunction }=\uparrow \text { OS } \\
\text { fibroblast } \geq \text { congenital heart defects in } \\
\text { DS }\end{array}$ \\
\hline $\begin{array}{l}\text { Bahado-Singh } \\
\text { et al. [37] (USA) }\end{array}$ & $\begin{array}{c}\text { 3-Hydroxybutyretate (oxidative } \\
\text { stress marker) } \\
\text { 3-Hydroxyisovalerate }\end{array}$ & Down syndrome & $\begin{array}{c}\text { Oxidative stress is thought to be one of the } \\
\text { most likely causes of neurotoxicity in DS }\end{array}$ \\
\hline
\end{tabular}

Zong et al. [33] Polymorphisms in glutathione S-

(China)

transferases (GSTs) GSTA1-69C/T

Telomere length (TL)

Peroxide levels

Gimeno et al., GSSH/(glutathione) GSH ratio

[38] (Spain) Cu/ZnSOD, MnSOD activity

Catalase activity

Glutathione peroxidase activity
Oxidative damage-early event in DS pathogenesis $\geq$ deleterious DS phenotypes (abnormal development, neuropathology)

Down syndrome

Recurrent spontaneous abortion (RSA)

No significant association between RSA and GSTs polymorphisms

\begin{tabular}{lccc}
\hline & & $->$ pathophysiology of DS \\
$\begin{array}{l}\text { Mukhopadhyay } \\
\text { et al. [42] } \\
\text { (India) }\end{array}$ & $\begin{array}{c}\text { Malondialdehyde (MDA) } \\
\text { Protein carbonyl (PC) }\end{array}$ & $\begin{array}{c}\text { Tracheesophageal fistula (TEF) } \\
\text { Anorectal malformation (ARM) }\end{array}$ & $\begin{array}{c}\uparrow \text { MDA, PC (products of lipid and protein } \\
\text { oxidation) = pathophysiology involves OS } \\
\text { Treatment with antioxidants = useful as a } \\
\text { preventive therapy }\end{array}$ \\
\hline
\end{tabular}

Sakai et al. [41] Reactive oxygen species (ROS)

(Japan)
$\mathrm{N}$-Acetyl-cysteine (NAC)
Down syndrome

Alteration of SOD1gene expression, $\mathrm{Cu} / \mathrm{Zn}$ SOD protein levels and other antioxidant enzymes (thioredoxin 1) $\geq$ poor proliferative capability of tissues in

DS (telomeric attrition, increased expression of Rcan1) - > $\uparrow$ OS - > pathophysiology of DS oxidation $)=$ pathophysiology involves OS preventive therapy

Tcof1 haploinsufficiency results in OSinduced DNA damage and neuroepithelial cell death

Maternal treatment with antioxidants minimizes cell death in the 
TABLe 3: Continued.

\begin{tabular}{|c|c|c|c|}
\hline References & Markers analyzed & Abnormalities investigated & Commentary \\
\hline & & & $\begin{array}{l}\text { neuroepithelium and substantially } \\
\text { ameliorates/prevents the pathogenesis of } \\
\text { craniofacial anomalies in } T \text { cof } 1^{+-} \text {mice }\end{array}$ \\
\hline $\begin{array}{l}\text { Yuan et al. [48] } \\
\text { (China) }\end{array}$ & $\begin{array}{l}\text { 8-Hydroxy-2' }{ }^{\prime} \text {-deoxyguanosine } \\
\text { (8-OHdG), protein carbonyl } \\
\text { (PC), and } 8 \text {-iso-prostaglandin } \\
\text { F2 } \alpha \text { (8-iso-PGF2 } \alpha)\end{array}$ & Neural tube defects (NTDs) & $\begin{array}{c}\uparrow 8 \text {-OhdG-without folic acid } \\
\text { supplements during the periconceptional } \\
\text { period } \\
\uparrow 8 \text {-OhdG_-pregnancies affected by } \\
\text { NTDs }\end{array}$ \\
\hline $\begin{array}{l}\text { Moore et al. [55] } \\
\text { (Turkey) }\end{array}$ & Reactive oxygen species (ROS) & Congenital malformations & $\begin{array}{c}\text { OS = harmful radicals attacking biological } \\
\text { molecules: DNA, lipids, proteins }\end{array}$ \\
\hline $\begin{array}{l}\text { Ozsurekci et al. } \\
\text { [56] (Japan) }\end{array}$ & $\begin{array}{c}\text { Reactive oxygen species (ROS) } \\
\text { TCOF1 gene }\end{array}$ & Treacher Collins syndrome (TCS) & $\begin{array}{l}\text { Review: role of Tcof } 1 \text { mutation in } \\
\text { embryonic craniofacial development } \\
\text { Genetic and environmental factors } \\
\geq \text { severity of craniofacial abnormalities, } \\
\text { prospect for prenatal prevention of } \\
\text { craniofacial anomalies }\end{array}$ \\
\hline $\begin{array}{l}\text { Maciejczyk et al. } \\
{[40] \text { (Poland) }}\end{array}$ & $\begin{array}{l}\text { Total antioxidant capacity (TAC) } \\
\text { Malondialdehyde (MDA) }\end{array}$ & $\begin{array}{c}\text { Ataxia-telangiectasia (A-T), } \\
\text { Bloom syndrome (BS) } \\
\text { Nijmegen breakage syndrome (NBS) }\end{array}$ & $\begin{array}{l}\text { A-T, BS, and NBS may be considered } \\
\text { mitochondrial diseases. Excess activity of } \\
\text { antioxidant enzymes and an insufficient } \\
\text { amount of low molecular weight } \\
\text { antioxidants indicate new } \\
\text { pharmacological strategies for treatment. }\end{array}$ \\
\hline $\begin{array}{l}\text { Pietryga et al. } \\
\text { [34] (Poland) }\end{array}$ & $\begin{array}{c}\text { Glutathione (GSH) } \\
\text { Glutathione S-transpherase } \\
\text { (GST) } \\
\text { S-Nitrosothiols (RSNO) } \\
\text { Trolox equivalent antioxidant } \\
\text { capacity (TEAC) } \\
\text { Total protein (TP) } \\
\text { Nitrites }\end{array}$ & $\begin{array}{l}\text { Chromosomal aberrations } \\
\text { Congenital malformations }\end{array}$ & $\begin{array}{c}\uparrow \mathrm{TP}, \mathrm{GST}, \mathrm{TEAC} \text {, and } \downarrow \text { GSH correlated } \\
\text { with the risk of chromosomal aberrations } \\
\text { and congenital malformations }\end{array}$ \\
\hline
\end{tabular}

Lead $(\mathrm{Pb})$

Aluminum (Al)

Liu et al. [43] Malondialdehyde (MDA)

(China) Supeoxide dismutase (SOD)

Glutathione peroxidase (GSH-

$\mathrm{Px})$

\begin{tabular}{|c|c|c|c|}
\hline $\begin{array}{l}\text { Cim et al. [46] } \\
\text { (Turkey) }\end{array}$ & $\begin{array}{c}\text { Glutathione }(\mathrm{GSH}) \\
\text { Catalase (CAT) } \\
\text { Malondialdehyde (MDA) }\end{array}$ & $\begin{array}{l}\text { Congenital malformations of the central } \\
\text { nervous system }\end{array}$ & $\begin{array}{c}\uparrow \text { MDA } \\
\downarrow \text { GSH and CAT }=\uparrow \text { OS in amniotic } \\
\text { fluid-associated with neural tube defects }\end{array}$ \\
\hline $\begin{array}{l}\text { Laforgia et al. } \\
\text { [36] (Italy) }\end{array}$ & $\begin{array}{c}\text { Oxidative stress } \\
\text { Reactive oxygen species (ROS) } \\
\text { Antioxidants }\end{array}$ & $\begin{array}{l}\text { Down syndrome } \\
\text { Heart malformation } \\
\text { Neural tube effect }\end{array}$ & $\begin{array}{c}\text { Review: fetal tissue-sensitive to oxidative } \\
\text { damage } \\
\text { OS }+ \text { impaired antioxidant } \\
\text { activity = congenital malformations } \\
\text { Antioxidants therapeutic approaches }\end{array}$ \\
\hline $\begin{array}{l}\text { Lin et al. [47] } \\
\text { (China) }\end{array}$ & $\begin{array}{c}\text { Benzo }[\alpha] \text { pyrene }(\mathrm{BaP}) \\
\text { Reactive oxygen species (ROS) } \\
\text { Superoxide dismutase (SOD) } \\
\text { Glutathione peroxidase (GPx) } \\
\text { Catalase (CAT) } \\
\text { 8-hydroxy2' deoxyguanosine } \\
\text { Total antioxidant capacity (TAC) } \\
\text { Malondialdehyde (MDA) }\end{array}$ & Neural tube defects & $\begin{array}{c}\mathrm{BaP} \text { exposure } \geq \uparrow \text { OS, apoptosis } \geq \text { NTDs } \\
\text { Protective effect of vitamin } \mathrm{E}\end{array}$ \\
\hline
\end{tabular}

Heavy metals $\geq \uparrow$ oxidative stress $\geq$ congenital heart disease
Congenital heart disease

neuroepithelium and substantially

ameliorates/prevents the pathogenesis of

$\uparrow 8$-OhdG-without folic acid period gnan NTDs

$=$ harmful radicals attacking biological Review: role of Tcof1 mutation in mbryonic craniofacial developmen $\geq$ severity of craniofacial abnormalities, craniofacial anomalies

A-T, BS, and NBS may be considered ivity of mount of low molecular weight antioxidants indicate new harmacological strategies for treatment.

$\uparrow$ TP, GST, TEAC, and $\downarrow$ GSH correlated and congenital malformations 
TABLe 3: Continued.

\begin{tabular}{|c|c|c|c|}
\hline References & Markers analyzed & Abnormalities investigated & Commentary \\
\hline $\begin{array}{l}\text { Engineer et al. } \\
\text { [45] (Canada) }\end{array}$ & $\begin{array}{c}\text { Review } \\
\text { Nitric oxide (NO) } \\
\text { Nitric oxide synthase (eNOS) } \\
\text { ROS } \\
\text { 8-hydroxyguanosine (8-OHG) }\end{array}$ & Congenital heart disease & $\begin{array}{c}\text { eNOS and NO_critical for property } \\
\text { morphogenesis of all major components } \\
\text { of the developing heart } \\
\uparrow \text { ROS-nonspecific damage and } \\
\text { permanent functional changes } \\
\text { 8-OHG-RNA damage causative factor } \\
\text { Hyperglycemia }=\uparrow \text { ROS } \\
\text { Treatment with Vit E and C }=\downarrow \text { rate and } \\
\text { severity of CHD }\end{array}$ \\
\hline
\end{tabular}

expression and activity of the main antioxidant enzymes in the study group were analyzed. The thesis regarding the effect of oxidant-antioxidant imbalance on the generation of genetic disorders such as trisomy 21 was confirmed. An increased GSSG/GSH ratio and high concentrations of protein peroxidation products in fibroblasts have been demonstrated. The obtained values correlated with the reduced antioxidant capacity of cells. The results obtained showed reduced levels of antioxidants that cooccurred with increased Rcan1 levels and telomere shortening, responsible for increased oxidative stress and cell cycle disorders of fibroblasts of fetal's with Down syndrome [38].

It has also been proven that the amniotic fluid, in which fetal cells with Down's syndrome are present, differs in oxidative status depending on the severity of the lesions and abnormalities that occur-especially nerve cell damage. Increased levels of oxidative stress, as indexed by increased protein oxidation, lipid peroxidation, reduction of glutathione (GSH) and thioredoxin levels, and induction of the heat-shock protein (HSP) response were associated with worse prognosis as to survival and normal development [39].

A relationship between oxidative stress and the occurrence of such abnormalities in the genome structure as Ataxiatelangiectasia (A-T), Bloom syndrome (BS), or Nijmegen syndrome (NBS) has also been demonstrated. High levels of reactive oxygen species (ROS) may be a major phenotypic hallmark in these diseases. The observed damages and other abnormalities, such as changes in the ultrastructure and function of cells, prove that we can consider analyzed diseases as mitochondrial. However, more research is needed to confirm whether antioxidants and free radical scavengers can improve the condition or extend the survival of patients [40].

Scientists conducting research on the pathogenesis of Treacher Collins syndrome have demonstrated the negative effects of ROS on developing progenitor neural crest cells. Depending on the degree of DNA damage, fetal death or abnormal development of the facial cranium occurred. The confirmation of the theory was the absence of a defect in the progeny of mammals undergoing antioxidant supplementation. High levels of ROS were the causative agent of facial cranial malformations [41].

The relationship of oxidative stress with the occurrence of cardiac malformations was also analyzed. After investigating the levels of oxidative stress markers in newborns with cyanotic and noncyanotic congenital heart defects, elevated levels of oxidative stress and reduced levels of antioxidants were found in sick patients. In addition, studies with increased levels of homocysteine and reduced levels of vitamin B12, glutathione as an antioxidant, and folate in pregnant patients with fetal heart disease have been published. Increased markers of oxidative stress in the study group suggests its participation in the etiopathogenesis of cardiac developmental abnormalities [42].

Analysis of the oxidative balance in fetuses with trisomy 21 and coexisting congenital heart defects showed an impairment of the mitochondrial respiratory chain, inhibition of Complex I, and consequently increased production of ROS. The analysis of the heart cell transcriptome with abnormalities showed that the function of genes responsible for the regular work of mitochondria is significantly reduced compared with the control group, suggesting their participation through oxidative stress in the manifestation of the defect [43].

Researchers also investigated the oxidative balance of the fetuses of mothers with preexisting diabetes who had heart defects (CHD), such as a defect in the ventricular or atrial septum, valve defects, or abnormal ventricular outflow tracts. Mouse models have shown that oxidative imbalance is a major determinant of CHD. Concentrations of nitric oxide (NO) and reactive oxygen species dependent on endothelial nitric oxide synthase (eNOS) are crucial for creating the right structures of the heart muscle, regulating various cellular and molecular processes. As a result, eNOS deficiency causes oxidative stress, CHD, and coronary artery malformations [44].

Fetal exposure of a pregnant woman to heavy metals, such as lead and aluminum, has also been shown to be negative by disturbing the prooxidative-antioxidant balance. It is associated with an increase in MDA concentration and a decrease in the level of antioxidants such as superoxide dismutase (SOD) and glutathione peroxidase (GPx) in fetal cord blood serum with congenital heart disease [45].

The association of oxidative stress on the development of congenital malformations of the central nervous system is also increasingly well known. They belong to the common and one of the most serious birth defects in fetuses. Numerous studies have been carried out confirming the relationship between oxidant-antioxidant imbalance and abnormal development of the nervous system. A negative effect of oxidative stress on cell differentiation and CNS development has been demonstrated [46, 47]. Increased ROS concentrations have been documented in such anomalies as holoprozencephalia or myelomeningocele. Reduced levels of antioxidants such as glutathione and catalase as well as increased levels of 
TABLE 4: Current studies concerning the influence of oxidative stress on adverse pregnancy outcomes.

\begin{tabular}{|c|c|c|c|}
\hline References & Markers analyzed & Abnormalities investigated & Commentary \\
\hline Bogavac et al. [49] (Serbia) & $\begin{array}{c}\text { Reduced glutathione (GSH) } \\
\text { Supeoxide dismutase (SOD) } \\
\text { Glutathione peroxidase } \\
\text { (GSH-Px) } \\
\text { Glutathione reductase (GSHR) } \\
\text { Glutathione S-transferase (GST) } \\
\text { Xanthine oxidase (XOD) } \\
\text { Lipid peroxidation (LP) }\end{array}$ & $\begin{array}{c}\text { Pregnancy-induced hypertension } \\
\text { (PIH) } \\
\text { Gestational diabetes mellitus } \\
\text { (GDM) } \\
\text { Bacterial vaginosis }\end{array}$ & $\begin{array}{l}\text { Different concentrations in a } \\
\text { variety } \\
\text { of conditions } \\
\text { Parameters of oxidative stress } \\
\text { in the amniotic fluid } \\
\text { could be altered in } \\
\text { certain pathological conditions }\end{array}$ \\
\hline Clerici et al. [31] (Italy) & $\begin{array}{c}\text { Total antioxidant capacity (TAC) } \\
\text { Thiolyte capacity } \\
\text { Prooxidant capacity }\end{array}$ & $\begin{array}{c}\text { Preeclampsia (PE) } \\
\text { Pregestational diabetes (DM) } \\
\text { Preterm birth (PTB) }\end{array}$ & $\begin{array}{c}\uparrow \mathrm{OS}=\text { pathological pregnancies } \\
\uparrow \text { prooxidant capacity } \downarrow \text { TAC } \\
\text { and thiolyte } \\
\text { capacity in pathological } \\
\text { pregnancies }\end{array}$ \\
\hline Yiyenoglu et al. [32] (Turkey) & $\begin{array}{c}\text { Total antioxidant capacity (TAC) } \\
\text { Total oxidant level (TOL) } \\
\text { Oxidative stress index (OSI) }\end{array}$ & Recurrent pregnancy loss (RPL) & $\begin{array}{c}\uparrow \text { TOL and OSI } \\
\downarrow \text { TAC in RPL group } \\
\text { OS plays a central role in the } \\
\text { etiopathogenesis of RPL }\end{array}$ \\
\hline Marseglia et al. [50] Italy & $\begin{array}{c}\text { Oxidative stress (OS) } \\
\text { Reactive oxygen species (ROS) }\end{array}$ & $\begin{array}{l}\text { Recurrent pregnancy loss } \\
\text { Preeclampsia preterm premature } \\
\text { rupture of membranes }\end{array}$ & $\begin{array}{l}\text { Review: free radical theory } \\
\text { of aging, abnormal placentation } \\
\geq \uparrow O S \\
\geq \text { recurrent abortions (RPL), } \\
\text { preeclampsia, } \\
\text { FGR, PTB, pPROM }\end{array}$ \\
\hline Ramkumar [57] (USA) & Reactive oxidative stress & $\begin{array}{c}\text { Preterm birth (PTB) } \\
\text { Premature rupture of membranes } \\
\text { (pPROM) } \\
\text { Inflammation }\end{array}$ & $\begin{array}{c}\text { OS affects cell aging, } \\
\text { inflammation, } \\
\text { pPROM, and consequently PTB } \\
\text { by } \\
\text { p38 mitogen-activated kinase } \\
\text { (p38MAPK) pathways }\end{array}$ \\
\hline $\begin{array}{l}\text { Jauniaux et al. [51] (United } \\
\text { Kingdom) }\end{array}$ & Pathophysiology review & $\begin{array}{l}\text { Miscarriage } \\
\text { Preeclampsia } \\
\text { IUGR }\end{array}$ & $\begin{array}{c}\text { Role of oxidative stress in } \\
\text { pathophysiology }\end{array}$ \\
\hline Sultana et al. [23] (Australia) & $\begin{array}{c}\text { Pathophysiology review } \\
\text { (30 publications) } \\
\text { Total antioxidant capacity (TAC), } \\
\text { total oxidant status (TOS), } \\
\text { lipid peroxidation (LP) }\end{array}$ & $\begin{array}{c}\text { IUGR } \\
\text { Preeclampsia } \\
\text { Preterm birth }\end{array}$ & $\begin{array}{l}\text { Role in pathophysiology of OS } \\
\text { and placental ageing }\end{array}$ \\
\hline Jauniaux et al. [52] (France) & Pathophysiology review & $\begin{array}{c}\text { Preeclampsia } \\
\text { IUGR } \\
\text { Spontaneous pregnancy loss } \\
\text { Gestational diabetes mellitus } \\
\text { (GDM) }\end{array}$ & $\begin{array}{l}\text { The effect of oxidative stress } \\
\text { on trophoblast cells }\end{array}$ \\
\hline Sultana et al. [54] (USA) & $\begin{array}{l}\quad n=30 \text { publikacji review } \\
\text { TAC, TOS (total oxidant status), } \\
\text { produkty peroksydacji lipidów }\end{array}$ & Preterm birth (PTB) & $\begin{array}{l}\text { Oxidative stress maybe } \\
\text { associated with PTB }\end{array}$ \\
\hline
\end{tabular}

malondialdehyde in fetal amniotic fluid with central nervous system development disorders have also been shown [48].

Publications on the pathophysiology of oxidative stress in congenital malformations are shown in chronological order in Table 3.

\section{Oxidative Stress in Pregnancy Complicated by Other Abnormalities}

Researches to date confirm that the balance of oxidativeantioxidative processes is important for proper implantation and embryo development, while uncontrolled production of oxygen peroxidation products can lead to embryo resorption, embryopathy, development of preeclampsia, or degeneration of the placenta resulting in inhibition of fetal growth, low birth weight, or even premature delivery. There are also reports confirming that the occurrence of some pregnancy complications, such as fetal growth restriction (FGR) or preeclampsia, may be associated with antioxidant deficiency $[49,50]$.

The proper development of the placenta, from conception, requires balanced oxygen metabolism. The relatively 
low oxygen pressure in the initially developing chorion is intended to prevent excessive ROS production, protecting the embryo and fetus against the harmful and teratogenic effects of free radicals [51].

The researchers showed differences in levels of oxidative stress markers in the placenta, as well as increased apoptosis and reduced trophoblast cell proliferation in patients who had a miscarriage in the first trimester of pregnancy compared to normal developing pregnancies. In these patients, transcriptomic studies showed reduced expression of the genes responsible for mitochondrial function in placental villi. The exact associations of oxidative stress on the placenta in early pregnancy loss remain unclear. However, it is known that in placental cell cultures from patients with early miscarriages, the level of stress in the structure of the endoplasmic reticulum is higher, and the response of endoplasmic reticulum (UPR) chaperone proteins, which are a repair mechanism, is less effective [52].

Numerous studies for gestational hypertension and preeclampsia have confirmed that the reactive oxygen species are working efficiently. The authors point to the significant importance of reducing the levels of such oxidants, e.g., vitamin $\mathrm{E}$ or $\mathrm{C}$ in this type of pregnancy pathologies. A significantly lower antioxidant effect of trolox-a substance derived from vitamin $\mathrm{E}$ on lipid peroxidation processes in the placenta of women suffering from preeclampsia-has been proven. And by analyzing endothelin-1 and lipid peroxides in the serum of pregnant women with hypertension, a decrease in the level of abnormal oxidation reaction substances in pregnant women with hypertension supplementing vitamin $\mathrm{E}$ was shown [53].

Fetal growth restriction has also been analyzed for the relationship between its occurrence and oxidative stress. It has been shown that damage resulting from ROS activity occurs mainly in membrane lipids, proteins, and nuclear and mitochondrial DNA. Plasma and tissue malondialdehyde (MDA) levels were used for this analysis, which is an indicator of lipid peroxidation and oxidative stress. MDA and xanthine oxidase (XO, ROS-producing enzyme) levels were higher in maternal plasma, umbilical cord plasma, and placental tissues of patients with IUGR-complicated pregnancy. 8-Hydroxy-2' -deoxyguanosine (8-OHdG) is one of the more commonly used oxidation markers as the effect of ROS on tissues. Its levels and redox-1 factor (redox regulator, responsible for repairing damaged DNA) are much higher in the placenta of patients in pregnancy complicated by FGR compared to a properly developing pregnancy. These patients also demonstrated different levels of antioxidant enzymes, resulting in an increase in SOD and GSH-Px activity and a decrease in CAT activity. Analysis of placental structure in patients with intrauterine growth retardation confirmed the theory of aging associated with prooxidative-antioxidant imbalance and the effect of ROS on trophoblast cells [23].

After analyzing several available publications on preterm labor, a relationship between its occurrence and the oxidative balance of the pregnant body was also demonstrated. Patients who gave birth prematurely (before 37 weeks of pregnancy) had increased values of the total oxidative capacity of the body and lipid peroxidation products, which were the most frequently analyzed markers. It was also associated with reduced levels of the mother's total antioxidant capacity [54].

Publications on the pathophysiology of oxidative stress in pregnancy abnormalities are summarized in chronological order in Table 4.

\section{Summary}

The integrative review has shown that reactive oxygen species (ROS) play an important role in the regulation of cellular signaling and genetic expression. Based on the results of previous studies between 2010 and 2020 and widely documented muta- and carcinogenic properties of oxidative DNA damage, we analyzed the relationship between oxidative stress and the occurrence of congenital defects, which in our opinion seems to be a potential causative factor. We also analyzed the contribution effects of oxidative stress on other complications of pregnancy, such as FGR, diabetes, or preeclampsia.

In conclusion oxidative stress is unquestionably linked to abnormalities in both the pregnant mother and fetal development. However, it is not yet possible to clearly establish and confirm that it is the causative factor, due to numerous doubts and the lack of a specific mechanism of action. The final statement requires further detailed research, especially of clinical significance.

\section{Abbreviations}

A-T: Ataxia-telangiectasia

AL: Aluminum

BS: Bloom syndrome

CAT: $\quad$ Catalase

CHD: $\quad$ Congenital heart defects

CNS: Central nervous system

DCFH: Dichlorofluorescin

DHR: Dihydrorhodamine

DM: $\quad$ Pregestational diabetes

eNOS: $\quad$ Endothelial nitric oxide synthase

FGR: $\quad$ Fetal growth restriction

GDM: Gestational diabetes mellitus

GSH: $\quad$ Glutathione

GSH-Px: Glutathione peroxidase

GSHR: Glutathione reductase

GSSG: Glutathione disulfide

GST: $\quad$ Glutathione S-transpherase

HE: Hydroethidine

HOBr: Subbromic acid

HOCl: Hypochlorous acid

HO2•: Hydroperoxide radical

HPF: $\quad$ Fluorescein

HSP: Heat-shock protein

$\mathrm{H} 2 \mathrm{O} 2$ : Hydrogen peroxide

LDL: Low-density-lipoprotein

LP: $\quad$ Lipid peroxidation

MDA: Malondialdehyde

NBS: Nijmegen syndrome

NK: Natural killer 


\begin{tabular}{|c|c|}
\hline NO: & Nitric oxide \\
\hline $\mathrm{OH} \bullet:$ & Hydroxyl radical \\
\hline OS: & Oxidative stress \\
\hline OSI: & Oxidative stress index \\
\hline OX: & Xanthine oxidase \\
\hline $\mathrm{O} 2 \bullet:$ & Superoxide anion radical \\
\hline PB: & Lead \\
\hline PE: & Preeclampsia \\
\hline PIH: & Pregnancy-induced hypertension \\
\hline PON1: & Paraoxonase \\
\hline PPROM: & Preterm prelabour rupture of membranes \\
\hline PPTD: & Postpartum thyroid dysfunction \\
\hline PTB: & Preterm birth \\
\hline PUFA: & Polyunsaturated fatty acids \\
\hline Rcan1 gene: & Regulator of calcineurin 1 \\
\hline $\mathrm{RO} \cdot:$ & Alkoxy radical \\
\hline ROO•: & Peroxide radical \\
\hline ROS: & Reactive oxygen species \\
\hline RPL: & Recurrent pregnancy loss \\
\hline RSA: & Recurrent spontaneous abortion \\
\hline SOD: & Superoxide dismutase \\
\hline TAC: & Total plasma antioxidant capacity \\
\hline TAS: & That total plasma antioxidant \\
\hline TCS: & Treacher Collins syndrome \\
\hline TOL: & Total oxidant level \\
\hline TRX: & Thioredoxin \\
\hline XOD: & Xanthine oxidase (XOD) \\
\hline 8-OHdG: & 8-Hydroxy-2' -deoxyguanosine. \\
\hline
\end{tabular}

\section{Data Availability}

Research article: Medline, Cochrane and Scopus databases

\section{Conflicts of Interest}

No conflict of interest regarding this publication.

\section{References}

[1] H. Sies, "Oxidative stress: a concept in redox biology and medicine," Redox Biology, vol. 4, pp. 180-183, 2015.

[2] G. Pizzino, N. Irrera, M. Cucinotta et al., "Oxidative stress: harms and benefits for human health," Oxidative Medicine and Cellular Longevity, vol. 2017, Article ID 8416763, 13 pages, 2017.

[3] U. Jacob and R. Dana, Oxidative stress and redox regulation, Springer, 2013.

[4] G. Bartosz, Second face of oxygen, PWN Scientific Publisher, 2013.

[5] H. Bilen, K. Altinkaynak, E. Sebin, H. Aksoy, and F. Akcay, "Serum YKL-40 and MDA levels in Behcet disease," The Journal of the Pakistan Medical Association, vol. 66, no. 10, pp. 1299-1302, 2016.

[6] S. Shahmohamadnejad, A. Vaisi-Raygani, Y. Shakiba et al., "Association between butyrylcholinesterase activity and phenotypes, paraoxonase192 rs662 gene polymorphism and their enzymatic activity with severity of rheumatoid arthritis: correlation with systemic inflammatory markers and oxidative stress, preliminary report," Clinical Biochemistry, vol. 48, no. 1-2, pp. 63-69, 2015.
[7] V. Jakuš, E. Sándorová, J. Kalninová, and B. Krahulec, "Monitoring of glycation, oxidative stress and inflammation in relation to the occurrence of vascular complications in patients with type 2 diabetes mellitus," Physiological Research, vol. 63, no. 3, pp. 297-309, 2014.

[8] P. Santulli, S. Chouzenoux, M. Fiorese et al., "Protein oxidative stress markers in peritoneal fluids of women with deep infiltrating endometriosis are increased," Human Reproduction, vol. 30, no. 1, pp. 49-60, 2015.

[9] E. Fernández, J. M. García-Moreno, A. Martín de Pablos, and J. Chacón, "May the thyroid gland and thyroperoxidase participate in nitrosylation of serum proteins and sporadic Parkinson's disease?," Antioxid Redox Signal, vol. 21, no. 15, pp. 2143-2148, 2014.

[10] J. Cuffe, Z. C. Xu, and A. V. Perkins, "Biomarkers of oxidative stress in pregnancy complications," Biomarkers in Medicine, vol. 11, no. 3, pp. 295-306, 2015.

[11] S. Mateen, S. Moin, A. Q. Khan, A. Zafar, and N. Fatima, "Increased reactive oxygen species formation and oxidative stress in rheumatoid arthritis," PLoS One, vol. 11, no. 4, p. e0152925, 2016.

[12] J. Z. Yenin, G. Serarslan, Z. Yönden, and K. T. Ulutaş, "Investigation of oxidative stress in patients with alopecia areata and its relationship with disease severity, duration, recurrence and pattern," Clinical and Experimental Dermatology, vol. 40, no. 6, pp. 617-621, 2015.

[13] L. Maschirow, K. Khalaf, H. A. al-Aubaidy, and H. F. Jelinek, "Inflammation, coagulation, endothelial dysfunction and oxidative stress in prediabetes - biomarkers as a possible tool for early disease detection for rural screening," Clinical Biochemistry, vol. 48, no. 9, pp. 581-585, 2015.

[14] R. S. Patel, N. Ghasemzadeh, D. J. Eapen et al., "Novel biomarker of oxidative stress is associated with risk of death in patients with coronary artery disease," Circulation, vol. 133, no. 4, pp. 361-369, 2016.

[15] M. Neyal, F. Yimenicioglu, A. Aydeniz et al., "Plasma nitrite levels, total antioxidant status, total oxidant status, and oxidative stress index in patients with tension-type headache and fibromyalgia," Clinical Neurology and Neurosurgery, vol. 115, no. 6, pp. 736-740, 2013.

[16] M. Solmi, N. Veronese, E. Manzato et al., "Oxidative stress and antioxidant levels in patients with anorexia nervosa: a systematic review and exploratory meta-analysis," The International Journal of Eating Disorders, vol. 48, no. 7, pp. 826841, 2015.

[17] L. K. Mandal, S. Choudhuri, D. Dutta et al., "Oxidative stressassociated neuroretinal dysfunction and nitrosative stress in diabetic retinopathy," Canadian Journal of Diabetes, vol. 37, no. 6, pp. 401-407, 2013.

[18] A. Çiftci, B. Yilmaz, S. Köklü et al., "Serum levels of nitrate, nitrite and advanced oxidation protein products (AOPP) in patients with nonalcoholic fatty liver disease," Acta Gastroenterologica Belgica, vol. 78, no. 2, pp. 201-205, 2015.

[19] H.-J. Eisele, P. Markart, and R. Schulz, "Obstructive sleep apnea, oxidative stress, and cardiovascular disease: evidence from human studies," Oxidative Medicine and Cellular Longevity, vol. 2015, Article ID 608438, 9 pages, 2015.

[20] J. Lipińska, S. Lipińska, J. Stańczyk et al., "Reactive oxygen species and serum antioxidant defense in juvenile idiopathic arthritis," Clinical Rheumatology, vol. 34, no. 3, pp. 451-456, 2015. 
[21] T. Nakamura, O. A. Prikhodko, E. Pirie et al., "Aberrant protein S-nitrosylation contributes to the pathophysiology of neurodegenerative diseases," Neurobiology of Disease, vol. 84, pp. 99-108, 2015.

[22] M. Tesauro, S. Nisticò, A. Noce et al., "The possible role of glutathione-S-transferase activity in diabetic nephropathy," International Journal of Immunopathology and Pharmacology, vol. 28, no. 1, pp. 129-133, 2015.

[23] Z. Sultana, K. Maiti, J. Aitken, J. Morris, L. Dedman, and R. Smith, "Oxidative stress, placental ageing-related pathologies and adverse pregnancy outcomes," American Journal of Reproductive Immunology, vol. 77, no. 5, p. 77(5), 2017.

[24] A. Bąk, "Roszkowski K; Oxidative stress in pregnant women," Archives of Perinatal Medicine, vol. 19, no. 3, pp. 155-155, 2013.

[25] K. Duhig, L. Chappell, and A. Shennan, "Oxidative stress in pregnancy and reproduction," Obstetric Medicine, vol. 9, no. 3, pp. 113-116, 2016.

[26] T. Moore, I. Ahmad, and K. Schmid, "Oxidative stress levels throughout pregnancy, at birth, and in the neonate," Biological Research for Nursing, vol. 21, no. 5, pp. 485-494, 2019.

[27] V. Toescu, S. L. Nuttall, U. Martin, M. J. Kendall, and F. Dunne, "Oxidative stress and normal pregnancy," Clinical Endocrinology, vol. 57, no. 5, pp. 609-613, 2002.

[28] P. A. Dennery, "Oxidative stress in development: nature or nurture?," Free Radical Biology and Medicine, vol. 49, no. 7, pp. 1147-1151, 2010.

[29] D. Hernández-García, C. D. Wood, S. Castro-Obregón, and L. Covarrubias, "Reactive oxygen species: a radical role in development?," Free Radical Biology and Medicine, vol. 49, no. 2, pp. 130-143, 2010.

[30] H. D. Mistry and P. J. Williams, "The importance of antioxidant micronutrients in pregnancy," Oxidative Medicine and Cellular Longevity, vol. 2011, 12 pages, 2011.

[31] G. Clerici, C. Slavescu, S. Fiengo et al., "Oxidative stress in pathological pregnancies," Journal of Obstetrics and Gynaecology., vol. 32, no. 2, pp. 124-127, 2012.

[32] Ö. B. Yiyenoğlu, M. G. Uğur, H. Ç. Özcan et al., “Assessment of oxidative stress markers in recurrent pregnancy loss: a prospective study," Archives of Gynecology and Obstetrics, vol. 289, no. 6, pp. 1337-1340, 2014.

[33] Z. Ch, Y. Sha, and H. Xiang, "Glutathione S-transferase A1 polymorphism and the risk of recurrent spontaneous abortion in Chinese Han population," Journal of Assisted Reproduction and Genetics, vol. 31, no. 3, pp. 379-382, 2014.

[34] M. Pietryga, P. Dydowicz, K. Toboła et al., "Selected oxidative stress biomarkers in antenatal diagnosis as 11-14 gestational weeks," Free Radical Biology and Medicine, vol. 108, pp. 517523, 2017.

[35] G. Pagano and G. Castello, "Oxidative stress and mitochondrial dysfunction in Down syndrome," Neurodegenerative Diseases, vol. 22, pp. 291-299, 2012.

[36] N. Laforgia, A. di Mauro, G. Favia Guarnieri et al., "The role of oxidative stress in the pathomechanism of congenital malformations," Oxid Med Cell Longev, vol. 2018, article 7404082, 12 pages, 2018.

[37] R. O. Bahado-Singh, R. Akolekar, R. Mandal et al., "Metabolomic analysis for first-trimester Down syndrome prediction," American Journal of Obstetrics and Gynecology, vol. 208, no. 5, 5, pp. 371.e1-371.e8, 2013.

[38] A. Gimeno, J. L. García-Giménez, L. Audí et al., "Decreased cell proliferation and higher oxidative stress in fibroblasts from
Down Syndrome fetuses. Preliminary study," Biochimica et Biophysica Acta, vol. 1842, no. 1, pp. 116-125, 2014.

[39] M. Perluigi, F. di Domenico, A. Fiorini et al., "Oxidative stress occurs early in Down syndrome pregnancy: a redox proteomics analysis of amniotic fluid," Proteomics. Clinical Applications, vol. 5, no. 3-4, pp. 167-178, 2011.

[40] M. Maciejczyk, B. Mikoluc, B. Pietrucha et al., "Oxidative stress, mitochondrial abnormalities and antioxidant defense in Ataxia-telangiectasia, bloom syndrome and Nijmegen breakage syndrome," Redox Biology, vol. 11, pp. 375-383, 2017.

[41] D. Sakai, J. Dixon, A. Achilleos, M. Dixon, and P. A. Trainor, "Prevention of Treacher Collins syndrome craniofacial anomalies in mouse models via maternal antioxidant supplementation," Nature Communications, vol. 7, no. 1, 2016.

[42] S. P. Mishra, B. Mukhopadhyay, A. N. Gongopadhyay, A. Rani, and R. Gavel, "Free radicals and antioxidants status in neonates with congenital malformation," Journal of Indian Association of Pediatric Surgeons, vol. 20, no. 4, pp. 179-183, 2015.

[43] Z. Liu, C. He, M. Chen et al., "The effects of lead and aluminum exposure on congenital heart disease and the mechanism of oxidative stress," Reproductive Toxicology, vol. 81, pp. 9398, 2018.

[44] C. Piccoli, A. Izzo, R. Scrima et al., "Chronic pro-oxidative state and mitochondrial dysfunctions are more pronounced in fibroblasts from Down syndrome foeti with congenital heart defects," Hum Mol Genet, vol. 22, no. 6, pp. 1218-1232, 2013.

[45] S. Engineer and F. Greco, "Say NO to ROS: their roles in embryonic heart development and pathogenesis of congenital heart defects in maternal diabetes," Antioxidants, vol. 8, no. 10, p. 436, 2019.

[46] N. Cim, H. E. Tolunay, E. Karaman et al., "Amniotic fluid oxidant-antioxidant status in foetal congenital nervous system anomalies," The Journal of International Medical Research, vol. 46, no. 3, pp. 1146-1152, 2018.

[47] S. Lin, A. Ren, L. Wang et al., "Oxidative stress and apoptosis in benzo[a]pyrene-induced neural tube defects," Free Radical Biology and Medicine, vol. 116, pp. 149-158, 2018.

[48] Y. Yuan, L. Zhang, L. Jin et al., "Markers of macromolecular oxidative damage in maternal serum and risk of neural tube defects in offspring," Free Radical Biology \& Medicine, vol. 80, pp. 27-32, 2015.

[49] M. Bogavac, N. Lakic, N. Simin, A. Nikolic, J. Sudji, and B. Bozin, "Biomarkers of oxidative stress in amniotic fluid and complications in pregnancy," The Journal Of MaternalFetal \& Neonatal Medicine, vol. 25, no. 1, pp. 104-108, 2011.

[50] L. Marseglia, G. D’Angelo, S. Manti et al., "Oxidative StressMediated Aging during the Fetal and Perinatal Periods," Oxidative Medicine and Cellular Longevity, vol. 2014, Article ID 358375, 2014.

[51] E. Jauniaux and G. J. Burton, "Le rôle du stress oxydant dans les pathologies placentaires de la grossesse," Journal de Gynécologie Obstétrique et Biologie de la Reproduction, vol. 45, no. 8, pp. 775-785, 2016.

[52] R. Aouache, L. Biquard, D. Vaiman, and F. Miralles, "Oxidative stress in preeclampsia and placental diseases," International Journal of Molecular Sciences, vol. 19, no. 5, p. 1496, 2018.

[53] J. Pasiński, A. Świerczewski, D. Estemberg, U. KowalskaKoprek, and A. Karowicz-Bilińska, "The Influence of vitamin 
$\mathrm{C}$ and $\mathrm{E}$ use on concentration of endothelin-1 and lipid peroxides in the serum of pregnant women with arterial hypertension," Polish Gynaecology, vol. 84, no. 1, pp. 32-37, 2013.

[54] T. A. Moore, I. M. Ahmad, and M. C. Zimmerman, "Oxidative stress and preterm birth: an integrative review," Biological Research for Nursing, vol. 20, no. 5, pp. 497-512, 2018.

[55] Y. Ozsurekci and K. Aykac, "Oxidative stress related diseases in newborns," Oxidative Medicine and Cellular Longevity, vol. 2016, Article ID 2768365, 9 pages, 2016.

[56] D. Sakai and P. A. Trainor, "Face off against ROS: Tcof1/Treacle safeguards neuroepithelial cells and progenitor neural crest cells from oxidative stress during craniofacial development," Development, Growth \& Differentiation, vol. 58, no. 7, pp. 577-585, 2016.

[57] R. Menon, "Oxidative stress damage as a detrimental factor in preterm birth pathology," Front Immunol, vol. 5, 2014. 